ÉGYPTE monde arabe

\section{Égypte/Monde arabe}

$21 \mid 1995$

Économie égyptienne et perspectives de paix au Proche-Orient

\title{
L'impact des politiques d'ajustement dans l'agriculture égyptienne
}

Muhammad Abu Mandur

\section{(2) OpenEdition}

\section{Journals}

Édition électronique

URL : https://journals.openedition.org/ema/411

DOI : 10.4000/ema.411

ISSN : 2090-7273

Éditeur

CEDEJ - Centre d'études et de documentation économiques juridiques et sociales

Édition imprimée

Date de publication : 31 mars 1995

Pagination : 183-187

ISSN : 1110-5097

Référence électronique

Muhammad Abu Mandur, "L'impact des politiques d'ajustement dans l'agriculture égyptienne ", Égypte/Monde arabe [En ligne], 21 | 1995, mis en ligne le 08 juillet 2008, consulté le 07 juillet 2022 URL : http://journals.openedition.org/ema/411 ; DOI : https://doi.org/10.4000/ema.411

Ce document a été généré automatiquement le 7 juillet 2022

Tous droits réservés 


\title{
L'impact des politiques d'ajustement dans l'agriculture égyptienne
}

\author{
Muhammad Abu Mandur
}

1 Compte tenu des spécificités de l'agriculture égyptienne et des prévisions à moyen terme, les politiques d'ajustement structurel peuvent-elles atteindre les objectifs qui leur ont été fixés? Peuvent-elles accroître les superficies cultivées et les rendements, l'investissement et la production, en rétablissant les incitations par les prix et en valorisant les avantages comparatifs du pays? Nous allons tenter de montrer dans cette étude que de telles politiques menacent au contraire de ralentir davantage la croissance, d'accroître les inégalités et d'accentuer la dégradation de l'environnement.

Les mesures d'ajustement accentueront certaines évolutions récentes, qui entraînent un gaspillage des ressources de l'État et la concentration de la richesse et du capital agricoles. Parmi ces évolutions, on rappellera: la hausse des prix des intrants et la baisse de leur qualité (faute de contrôle) qui réduisent l'accès des paysans à ces intrants; la mauvaise répartition de l'eau entre les parcelles, faute d'assolement; l'utilisation de pesticides différents sur des parcelles voisines qui réduit les rendements et pollue l'environnement; la stagnation des ventes intérieures et la chute en valeur des exportations agricoles; la baisse des revenus des petits exploitants et des salaires ouvriers; la constitution de monopoles privés; la libéralisation du régime foncier qui rend la répartition de la structure foncière plus inégale, et augmente le nombre de paysans sans terre; la coordination insuffisante entre les centres de recherche et les coopératives agricoles, qui limitent l'amélioration des rendements; la participation décroissante des fermes d'état à la production nationale.

3 La réforme économique de l'agriculture égyptienne est présentée comme le remède nécessaire pour développer les cultures vivrières, industrielles et d'exportation, stopper la détérioration de la balance commerciale agricole et celle du taux d'autosuffisance alimentaire. La Banque mondiale considère que la croissance agricole, qui est tombée à 1,7\% en 1989/90 (FMI, 1992), est entravée parce que l'État détient près 
de $10 \%$ des terres cultivées, gère de nombreuses entreprises de production et de commercialisation, subventionne les agriculteurs directement, surévalue la monnaie, bonifie les taux d'intérêts, et fixe les prix intérieurs en dessous des prix internationaux. La Banque qualifie de "prélèvement indirect » de l'État sur l'agriculture l'écart entre prix intérieurs et extérieurs, qu'elle l'évalue à 5,5 milliards LE en 1985. Elle affirme que les distorsions de prix favorisent le gaspillage d'engrais, de pesticides et de machines agricoles et découragent l'investissement et la production dans les cultures stratégiques (coton, riz, maïs). Elle considère que la mauvaise gestion des intrants agricoles, du marché et du commerce extérieur est due à l'intervention excessive de l'État et de ses monopoles.

4 Depuis le début de l'application du programme d'ajustement en 1991, de nombreuses réglementations ont été supprimées pour l'ensemble des cultures, à l'exception du coton et de la canne à sucre : l'assolement obligatoire, la fixation des prix des produits par l'État, la bonification des taux d'intérêts, le monopole de la Principal Bank for Development and Agricultural Crédit (PBDAC) sur la commercialisation de la plupart des intrants de base et leur subvention. De plus, le prix du coton a été relevé, pour la saison 1992/93, à 66\% de son prix d'exportation, et la subvention sur les pesticides doit être réduite progressivement en 1994. Des terrains et entreprises d'État ont été privatisés et la libéralisation du commerce extérieur étendue. Le programme d'ajustement prévoit la libéralisation totale du régime foncier pour 1997, après avoir relevés à partir de la saison 1992/93 de 200\% les baux agricoles légaux, fixés depuis les années 1960 à 7 fois la valeur de la taxe foncière.

5 La Banque mondiale (1992) et l'ambassade des États-Unis (1993) imputent la hausse des taux de croissance et d'autosuffisance du blé, du maïs, du riz et du coton en 1991/92 et 1992/93 aux mesures de libéralisation. De fait, le Ministère de l'Agriculture a distribué des semences à haut rendement et relevé les prix d'achat des récoltes, ce qui a rendues ces quatre produits plus rentables que d'autres cultures. C'est donc l'intervention de l'État, et non son retrait, qui est à l'origine des progrès constatés, jusqu'à la chute des prix mondiaux des produits considérés. Le gouvernement s'est ainsi trouvé contraint de refuser d'acheter les récoltes de maïs en 1992, de riz et de coton en 1993, aux prix qu'il avait lui-même fixés en début de saison. En réaction, les paysans ont réduit les superficies cultivées de ces trois produits lors de la saison suivante.

6 La Banque mondiale prévoyait en 1991 une baisse future des revenus des petits agriculteurs. Elle se base sur le fait que les salaires réels des ouvriers agricoles ont baissé d'environ 60\% entre 1985 et 1991, tandis qu'augmentaient les revenus des propriétaires terriens (Stratégie pour l'agriculture égyptienne dans les années 90, 1992). Elle estime que la part des exploitations de moins de deux feddans ( 1 feddan $=0,42$ ha, NDLR) qui constituaient $57,5 \%$ des exploitations au dernier recensement agricole publié en 1981-82, s'est accrue depuis, du fait du morcellement lié aux successions.

7 Les prix des différents engrais chimiques ont été relevés, de 1987 à 1993, entre 350\% et 667\%. Ceux des semences ont crû entre 32\% (graines de soja) et $40 \%$ (graines de coton). Les prix des pesticides et des machines agricoles ont également augmenté entre 1988 et 1992. Suppression des subventions directes, hausse des prix des matières premières importées et relèvement des taux d'intérêt ont fait chuter de $28 \%$ les demandes de crédit en 1991/92. La consommation d'engrais azotés et de semences a baissé de plus de $40 \%$, et le taux de remboursement des emprunts a diminué ('Alî, 1993). Selon la Banque mondiale, la hausse des prix des intrants et du coût du crédit pourrait freiner 
l'adoption, par les petits producteurs, de systèmes de culture plus rentables, l'utilisation de technologies modernes et l'investissement sur les terres nouvelles. Si ces hausses réduisent trop les consommations intermédiaires les rendements en pâtiront.

8 La production et des exportations agricoles ont peu de chance de décoller dans un avenir proche. En effet, le coton égyptien, premier produit agricole d'exportation, est plus cher que son principal concurrent, subventionné par l'État. Les fruits et de légumes sont pénalisées par les techniques de manutention et d'emmagasinage obsolètes et la non-conformité des produits frais égyptiens aux normes internationales. Les importations alimentaires de l'Égypte (blé, sucre et huiles végétales) sont moins sensibles aux variations de changes que ses exportations agricoles, pour lesquelles la concurrence est très élevée. Les politiques monétaires ne peuvent seules stimuler les exportations. L'impossibilité pour les petits exploitants d'accéder au crédit diminue l'impact des incitations par les prix sur la productivité. La production et les structures commerciales ne pourront s'adapter aux nouvelles politiques fiscales et monétaires. Les exportations agricoles ont d'ailleurs baissé de 407 millions de dollars en 1989/90 à environ 355 millions de dollars en 1991/92, selon le Rapport de l'ambassade des ÉtatsUnis sur la situation agricole en 1993.

9 Cinq firmes privées inexpérimentées ont remplacé le monopole public de vente des engrais par un oligopole (Business Monthly, oct. 1993). Privatiser la vente des semences et des pesticides importés sans en contrôler la qualité menace l'environnement, la santé publique et la conformité aux normes d'exportation.

10 Ce sont l'irrigation pérenne et l'emploi massif des engrais et des semences à haut rendement qui sont responsables de l'accroissement des rendements des cultures principales. L'agriculture égyptienne dépend totalement de l'irrigation pérenne par les eaux du Nil sur les terres anciennes de la Vallée du Nil et du Delta. L'agriculture y est intensive, avec une moyenne de deux cultures par an sur chaque parcelle, ce qui use les sols. Les exploitations sont contigües et très petites (en moyenne 0,52 feddan au recensement agricole de 1981/82) et l'État dirigeait l'assolement, la distribution des semences, engrais et pesticides par bassins d'irrigations, regroupant différentes exploitations. La suppression de l'assolement sans remembrement va laisser la place à un système de cultures hétérogènes. Or, le morcellement des parcelles ne permet pas de cultiver côte à côte dans un même bassin des produits dont les dates d'irrigation ou les traitements pesticides diffèrent. La disparition de l'assolement risque donc de voir baisser les rendements et croître la pollution.

11 La libéralisation des baux risque de pousser de nombreux fermiers, qui constituaient $37,5 \%$ des exploitants en 1981-82, à abandonner leurs fermages. Si c'est le cas, la taille de leurs exploitations se limitera à leur propriété et ils grossiront les rangs des ouvriers agricoles. Elle risque également de favoriser, d'une part. la concentration de la propriété foncière et la précarité des fermages et, d'autre part, le développement du métayage, décourageant les investissements à long et à moyen terme et l'adoption des technologies modernes. Pour réussir, la réforme doit comprendre un réseau efficace d'information des paysans, renforcer le rôle des coopératives dans la production et le marketing, empêcher l'émergence de monopoles privés et la stagnation de la productivité. Comme les sociétés publiques de bonification des terres et d'agroalimentaire sont endettées, leurs dettes devront être déduites à la vente de leurs actifs. Leur privatisation risque d'entraîner une cessation ou un changement d'activité. Les 
licenciements devront être compensés par des reclassements ou des dédommagement financier. La privatisation accentuera la concentration des richesses entre les mains d'une minorité, la plupart des citoyens ne pouvant y participer. La vente des terres arables appartenant à des sociétés excluera certainement les agriculteurs démunis et conduira pour finir à la concentration de la propriété foncière sur un faible pourcentage de propriétaires.

Traduit de l'arabe par Mona Nias.

\section{BIBLIOGRAPHIE}

Al-Din G., "Fertilizers Industry", Business Monthly, Journal of the American Chamber of Commerce, n0 9. Le Caire. 1993.

Ali M., the Impact of Economie Reform on the Principal Bank for Development and Agricuttural Credit in Egypt, Banque principale pour le développement et le crédit agricole (PBDAC), Giza, 1993

Ambassade des États-Unis en Égypte. Foreign Economie Trends and their Implications for the United States, Report for tbe Arab Republic of Egypt et Agricultural Situation Annual Report, Le Caire, 1993.

Beshay A., "An Evaluation ot Prices of Major Agricultural Commodities in Relation to World Prices", Conférence sur la Réforme de la politique agricole en Égypte. Ministère de l'Agriculture et de la bonification des terres, Giza, 24-25 juin 1989.

FAO, Production Yearbook, vol. 44, Rome, 1990.

Fonds monétaire international, Recent Economie Development, Arab Republic of Egypt, Washington D.C.; 5 août 1992.

Khedr H. et ali., "Evaluation of Egyptian Agricultural sector", Conférence sur la Réforme de la politique agricole en Égypte. Ministère de l'Agriculture et de la bonification des terres, Giza, 24-25 Juin 1989.

Ministère de l'Agriculture, Recensement agricole 1981-82, Giza, 1989.

Banque mondiale, Arab Republic of Egypt, an Agricultural Strategy of the 1990s, Report n 11083 - EGT, Washington D.C., 11 décembre 1992.

INDEX

Mots-clés : agriculture

\section{AUTEUR}

MUHAMMAD ABU MANDUR

Université du Caire 